\title{
Developing 21st Century Competencies of Marginalized Students Through the Use of Augmented Reality (AR)
}

Janette Hughes and Melanie Maas

\begin{abstract}
In this article, we share an ethnographic case study of how we worked with a small group of marginalized grades 6,7 , and 8 students to both explore and create augmented reality (AR) to produce a class cookbook. We discuss how using AR helped students develop digital literacies skills and 21 st century competencies, while at the same time, integrating AR into the students' life skills component of their programming helped them also develop cooking skills and basic nutrition awareness. The findings suggest that AR has great potential in educational contexts and can be used in cross-disciplinary ways that go beyond STEM-focused programming.
\end{abstract}

\section{Background}

While virtual reality (VR), "completely immerses users in a synthetic world without seeing the real world" (Carmigniani et al., 2011, p. 342), augmented reality (AR) superimposes information or virtual objects into the real world allowing a reality where virtual objects seem to coexist in the same space with the real world (Azuma, 1997). Although AR and VR technologies have been around for some time now, they are just recently being embraced in educational contexts (Bujak et al., 2013). The authors of the 2017 Horizon Report (K-12 Edition) predict that the time-to-adoption horizon for VR in schools is two to three years and Goldman Sachs estimates that, "VR could reach 15 million learners by 2015" (Freeman, Adams Becker, Cummins, Davis, \& Giesinger, 2017). Although not specifically mentioned in the Horizon Report, AR perhaps offers greater potential for student learning from a creation or production perspective. With the emergence of easy-entry, drag-and-drop platforms such as Aurasma, students can create their own augmented reality experiences with minimal effort, producing professional looking results. In this ethnographic case study, we explore the use of AR technology with marginalized students, in a non-STEM related class as another multimodal vehicle for students to develop and demonstrate 21 st century learning competencies such as creative/critical thinking and problem solving, communication, collaboration, self-directed learning, and citizenship (Ontario Public Service, 2016). With Ontario Premier Kathleen Wynne's September 6th, 2017 announcement that curriculum and report cards would be updated to reflect "transferable life skills," the need to explore learning experiences that will promote the development of these skills and competencies is even more pressing than before. 


\section{Literature Review/Overview}

A number of industries, including healthcare and aviation, use VR and AR to train learners in areas such as surgery preparation, driving and flying, design and development, neuroscience, and rehabilitation and teleoperation (Mihelj, Novak, \& Beguš, 2014; Lindgren \& Johnson-Glenberg, 2013). The benefits of learning through AR include increased content understanding of spatial structure and function, learning of language associations, long-term memory retention, improved physical task performance, and increased motivation and engagement (Bacca, Baldiris, Fabregat, Graf, \& Kinshuk, 2014; Lee, 2012; Lindgren \& Johnson-Glenberg, 2013; Radu, 2014). Although the potential uses for AR technologies in education are many, some educators question how schools, which have struggled to integrate even basic computer technology, will overcome K-12 technology integration barriers (Herold, 2014).

Although educational applications are only just emerging, research into educational uses of AR (and related VR and MR technologies) has increased significantly recently (Bacca et al., 2014; Chen, Liu, Cheng, \& Huang, 2016; Lindgren \& Johnson-Glenberg, 2013; Wu, Lee, Chang, \& Liang, 2013). A number of studies have highlighted the potential for these technologies to provide deeper and more authentic learning opportunities by offering a unique mix of both real and virtual environments (Adams Becker, Cummins, Freeman \& Rose, 2017; Bower, Howe, McCredie, Robinson, \& Grover, 2014; Freeman et al., 2017; Lindgren \& Johnson-Glenberg, 2013; Kerawalla, Luckin, Seljeflot, \& Woolard, 2006; Teichner, 2014; Wu et al., 2013). The ability for these technologies to afford interaction with material in 3D, physical and cognitive immersion with learning material, and collaborative and interactive work on complex and abstract concepts, has been highlighted (Adams Becker et al., 2017; Bower et al., 2014; Lindgren \& Johnson-Glenberg, 2013; Kerawalla et al., 2006; Teichner, 2014; Wu et al., 2013).

Today's knowledge-based economy requires that learners develop skills that enable them to effectively navigate and participate in our digital world (Larson \& Miller, 2011; Kong et al., 2014; Voogt \& Pareja Roblin, 2012; Zhao, 2015). The skill sets needed by employees today are not inherently different from those needed in the past. Changes in the job market have resulted in greater attention to the necessity of certain employability skills that have become known as 21 st century skills (21CS) or 21 st century competencies (Assefa \& Gershman, 2012; Chu, Reynolds, \& Tavares, 2016; Kong et al., 2014; Larson \& Miller, 2011; Voogt \& Pareja Roblin, 2012). Within 21CS, there are three general skill sets: 1) Learning and Innovation; 2) Digital Literacies (Information, Media, and Technology Skills); and 3) Life and Career skills (Chu et al., 2016). Specific individual skills further define these three general skill sets to support those aptitudes considered necessary for the 21 st century (Chu et al., 2016; Voogt \& Pareja Roblin, 2012).

\section{Theoretical Considerations}

AR and VR by their very nature have "the potential to both engage and excite" (Thornton, Ernst, \& Clark, 2012, p. 18). As cited by Wu et al. (2013), "The nature of these instructional approaches...is quite different from the teacher-centred, delivery-based focus in conventional teaching methods" (p. 47). 
According to research thus far, "AR could enable (1) learning content in 3D perspectives, (2) ubiquitous, collaborative and situated learning, (3) learners' sense of presence, immediacy, and immersion, (4) visualizing the invisible, and (5) bridging formal and informal learning" (p. 43). A number of recently published studies about AR in education have appeared and the number is increasing each year, particularly over the past four years (Bacca et al., 2014). Research into higher education and distance education has highlighted the capability for AR and VR to remove geographical boundaries and allow, "teachers and learners who are separated by distance [to] engage in social activity in learning" (Hew \& Cheung, 2010, p. 34). More recently, illustrations of how AR and VR might provide experiences that are more engaging are beginning to be considered (Bower et al., 2014).

Constructivist theories suggest that learners learn better through active engagement in learning (Comstock, 2013). AR and VR can be considered constructivist due to their ability to allow students to work collaboratively and in an interactive way (Bower et al., 2014; Kerawalla et al., 2006; Teichner, 2014). There are a number of learning theories that may be considered in exploring AR and VR in education, including social learning theory, game-based learning, just in time learning, self-directed learning, and personalized learning. AR and VR environments offer information via multiple senses, such as auditory, visual, and spatial, thus providing a differentiated learning environment that may offer greater engagement, perhaps resulting in further transfer and deeper understanding.

Redefining literacy. Historically, literacy has referred to the ability to read and write. Barone (2015) highlighted foundational literacy knowledge as achieving a "full orchestration of reading knowledge knowledge of letters and sounds, knowledge of decoding, fluency and prosody, and the integration of all elements" (p. 2). These foundational skills are a part of literacy; however, the way in which learners acquire these skills are different with technology (Downing, 2005; Barone, 2015). As information is accessed in formats outside of printed literature, the impact of technology is changing the very definition of literacy. AR and VR technologies are well positioned to inform and impact this new "multimodal literacy [which] includes interpretation of visual, written and performative aspects of text" (Barone, 2015, p. 2) as well as the development of literacy skills through the use of social networking (Barden, 2014; Barone, 2015; Minton, 2002). Literacy in the 21 st century refers to more than just reading text in a printed book; it includes the myriad of ways a learner can access information and communicate through technology.

Multimodal learning. Accessing and manipulating information in multiple modes or formats including auditory, visual, and physical, or through text and non-text based means, illustrates the basic concept of multimodal learning. Considering that AR applications allow for virtual elements to be superimposed in real-world environments, it is fitting that $A R$ (and VR and MR) technologies be considered by their very nature to hold many possibilities for multimodal learning. The capabilities for AR solutions to present information in alternate formats may provide an opportunity such as that cited by Erten and Savage (2012), to "adapt the school environment to meet the needs of an individual student, rather than making the student fit in the school system" (p. 222). 
AR has been used successfully for some time now to provide simulated environments where learners in fields such as medicine, engineering, and space travel can practice various scenarios in a safe environment to learn and adjust their reactions and operations ahead of their real-world interactions (Gelenbe, Hussain, \& Kaptan, 2005). Additionally, AR has been examined in relation to its ability to offer augmented feedback on learners' experiences (Sigrist, Rauter, Riener, \& Wolf, 2013), as well as a promising means to address the needs of a neurodiverse population (Bacca et al., 2014). Lee (2012) predicts that as AR advances as a technological tool for learning and training, these technologies will continue to be developed and applications for education will be realized within a few years.

\section{Methodology}

Ethnographic case study. Using an ethnographic case study method, the researchers were immersed within a class comprising marginalized students who faced a variety of personal and learning challenges. This approach is conducive to this study, which positioned the teacher and student participants as coresearchers and cocreators of knowledge. We drew on multiple sources of data and used methods that prompted participants to share their meaning-making processes throughout the study.

\section{Research Procedure}

Setting. There were two primary settings for this study-a makerspace research lab in a Faculty of Education at a university in southern Ontario, Canada and a school classroom. Within the makerspace lab, there were a number of additional technologies available including 3D printers, MacBooks, iPads, iPods, programmable robots (i.e., Sphero and Ozobot), electronic circuitry components, wearable tech, and other makerspace-related materials. The school classroom was a traditional classroom that also had an interactive whiteboard and each student in the class had a school board supplied laptop (Lenovo).

Participants. The class was a Section 20 classroom, which comprises students who are part of a government approved care, treatment, and custody program. The purpose of selecting these students was to evaluate the ease of use of AR technologies while researching whether this study supported the "at promise" (Swadener, 2010) potential of these students. The findings of this study are limited due to the study size and student group.

These students come from a variety of backgrounds and have a variety of challenges including learning disabilities and/or behavioural challenges. The class of students who participated in this study comprised three girls and two boys. The students in the class ranged in age from 11 to 13, and the class covered grades 6,7 , and 8 . The class included a classroom teacher, who focused on academics, as well as a child and youth worker who oversaw the students' "care, custody, and treatment" components of the program.

Data sources. Data were collected in multiple formats over the duration of the study. These sources included unstructured pre- and post-interviews, field notes, voice recordings, voice typing, and typed observations, digital pictures and video of student presentations, videos and pictures of the students' work, informal discussions, and meetings with the teacher following each session to discuss observations 
from the session and future planning. Analysis of the data was completed throughout the study and was reflected upon regularly in order to analyse the students' progress over time.

Technology used. The technology used in this study included MacBook computers, Lenovo Computers, a variety of smartphones such as Samsung Galaxy S6 and iPhone, iPods, and iPads. This technology was selected based on preference for low-cost offerings and used existing equipment available in the school and makerspace.

Sequence of events. Due to the class being a Section 20 care, custody, and treatment class, students ranged in age, grade level, and skill set. As such, the research team needed to establish a common curriculum that could bridge knowledge and skill levels while effectively engaging the whole group. Additionally, because AR technologies are fairly new from a K-12 educational perspective, existing curricula using these technologies were limited. The research team's goal was to explore how the technology might integrate into existing curriculum. The study used the class's life skills curriculum focus to create an AR recipe book integrating AR technology with the life skills of health, cooking, and nutrition. As part of the creation of the AR recipe book, the students were provided with the opportunity to learn basic cooking skills, to eat healthy meals, to read and interpret a nutritional label, to expand their knowledge of healthy choices, and to acquire digital literacy skills to then translate their learnings into the creation of a recipe book that included augmentations (additional text, photos, videos). Table 1 outlines the weekly lesson plan for creating the AR recipe book, while Figure 1 provides an image of the checklist used by the class to track its progress.

\section{Table 1}

Weekly lesson plan outline for the creation of the augmented reality recipe book

\begin{tabular}{|c|c|l|}
\hline Week & Focus & Description \\
\hline 1 & Intro & Introductory Meeting with Teacher \\
\hline 2 & Intro & $\begin{array}{l}\text { Planning Meeting with Teacher } \\
\text { Introduction to class, discussions with Instructor/First Week at university lab with Class - Intro to VR/AR/ }\end{array}$ \\
\hline 3 & Intro & Explain the concepts of AR \& VR Technologies, introduction to the technology \\
\hline 4 & AR & Introduction to Aurasma - Build your own AR \\
\hline 5 & AR & Mr. Morris Lessmore (Read/Movie/AR) AR Elements/Anatomy \\
\hline 6 & AR & AR Books Exploration/AR Daqri (Chemistry Blocks \& Heart) \\
\hline 7 & AR & AR Aurasma - Tutorial/Create your own Aurasma (Free Choice) \\
\hline 8 & AR & Introduction to class Recipe Book Project - Creation of Plan for cooking, photos, recipes, etc. \\
\hline 9 & AR & AR Aurasma - Create your own Aurasma (Healthy Choices - Before and After) \\
\hline 10 & AR* & AR Recipe Book - Photos, Recipes, Cooking \\
\hline 11 & AR* & AR Recipe Book - Photos, Recipes, Cooking \\
\hline 12 & AR* $^{*}$ & AR Recipe Book - Photo Augmentations \\
\hline 13 & AR* $^{*}$ & AR Recipe Book - Created recipe template so all are using the same format \\
\hline 14 & AR* $^{*}$ & AR Recipe Book - Recipes \\
\hline 15 & AR* & AR Recipe Book - Photo Augmentations \\
\hline 16 & AR* & AR Recipe Book - Cooking is finished, ensure all pictures are accessible, ensure we have all the recipes \\
\hline 17 & AR* $^{*}$ & AR Recipe Book - Photo Augmentations \\
\hline 18 & AR* $^{*}$ & AR Recipe Book - Cooking is finished, ensure all pictures are accessible, ensure we have all the recipes \\
\hline 19 & AR* $^{*}$ & First Print of Recipe Book - Changes, new pictures to use, challenges with augmentations, etc. \\
\hline 20 & AR* $^{*}$ & AR Recipe Book - Photo Augmentations \\
\hline 21 & AR* $^{*}$ & AR Recipe Book - Final Print \\
\hline 22 & AR* $^{*}$ & AR Recipe Book - Book Launch Party \\
\hline
\end{tabular}

Note: Use of additional software programs required for this section included: Microsoft PowerPoint and Word, Gmail, Aurasma, Microsoft Photo Editor, (cut, paste, crop, save, attach file, browse folders) 


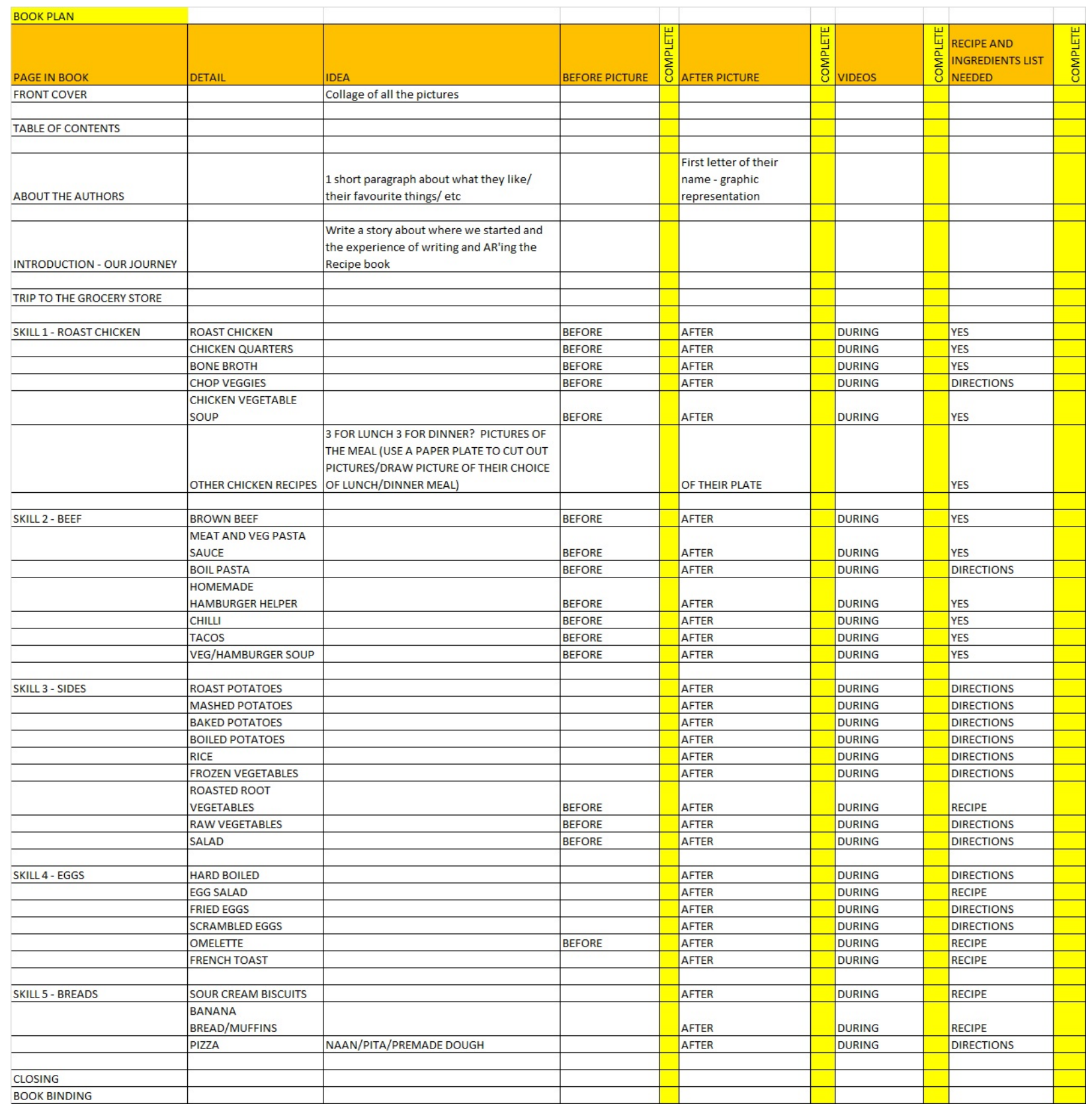

Fig. 1: Checklist by Recipe Book Chapter of Required Photos and Recipes needed for the creation of the Augmented Reality Recipe Book. 


\section{Findings}

Through analysis of field notes, the study sequence of events, video, audio, and field notes, as well as written and oral student reflections, this section presents the findings related to the class's AR recipe book project in which the AR technology Aurasma (Hewlett-Packard Development Company, 2016) was utilized within a life skills curriculum. The initial demonstration of the Aurasma software highlighted the need for digital citizenship instruction when dealing with online content to discuss copyright and accreditation of others' work. The use of the Aurasma software required the research team to instruct the students on a number of basic digital literacy skills as outlined in Figure 2.

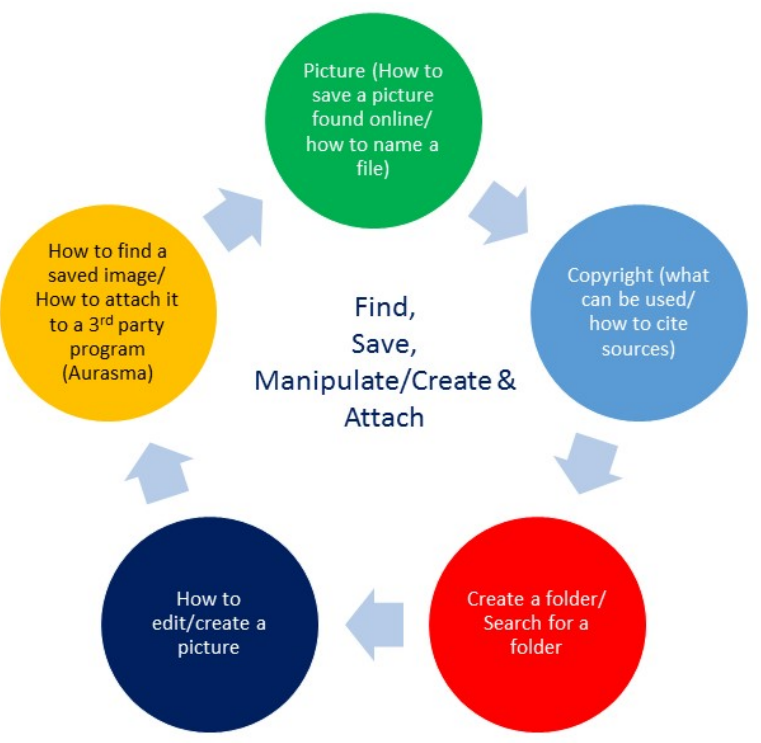

Fig. 2: Basic digital literacy skills needed for creating augmented reality images through Aurasma.

Through the use of Aurasma AR software, a wide variance in students' digital skillsets was observed and addressed through differentiated instruction. The skills the students acquired are outlined in Figure 3.

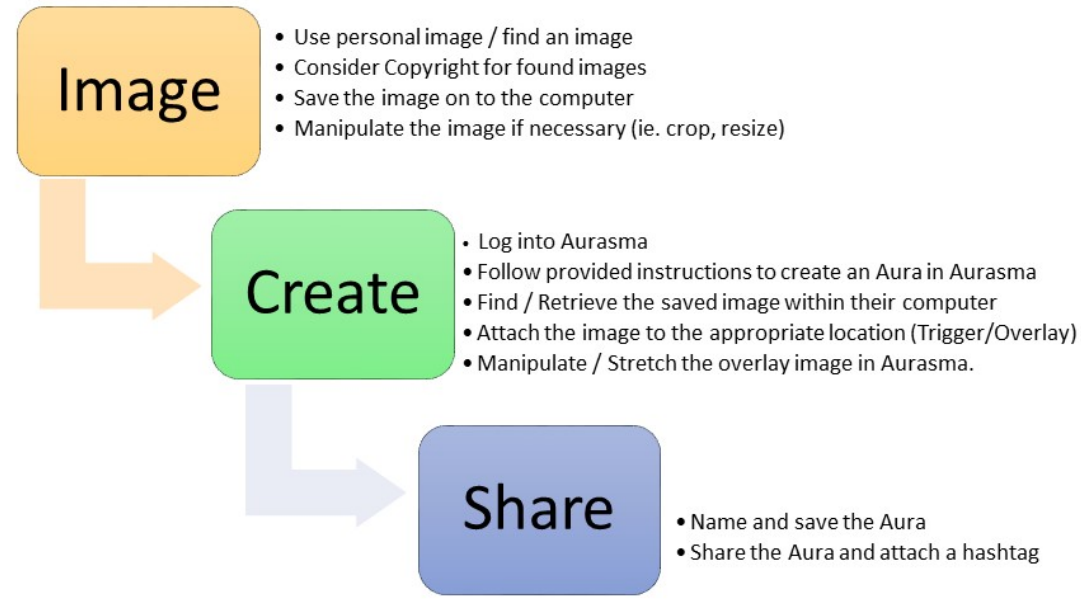

Fig. 3: Basic digital literacy skill sets acquired by students during the creation of augmented reality images through Aurasma. 


\section{Development of Digital Technology Skills}

The creation of the AR recipe book incorporated the acquisition and use of digital technology skills with a life skills curriculum. The students were found to focus on the life skills curriculum while being seemingly oblivious to the technology skills they were developing and using. The use of AR was explored within this study from both creation and consumption perspectives. At the beginning of the study, the students did not understand the connection between the AR apps and the images. The study used the free AR creation software Aurasma and overall findings may serve to provide insight into effective use of similar software programs. Of key interest to the research team was that, although the students in this class have regular access to laptops, they needed very basic instruction on basic digital literacy skills in order to effectively utilize the Aurasma software and thus create augmentations.

The creation of the recipe format involved the use of Microsoft PowerPoint and Word software. The students needed to be taught how to find PowerPoint and Word on their computer, how to open these applications, how to save a file, how to name a file, how to create a folder on their computer, and how to find a file from within a different program. It should be noted these are students who have had school district allocated laptops over a number of years and are not new to laptop technology; however, they lacked very basic computer navigation skills. We found that throughout the duration of the study, common digital skills needed to be taught repeatedly as the students did not have this knowledge ingrained. There were repeated instances throughout the project involving lost documents; the student had completed the work, though they had saved the document, and on searching the computer, we often located the document in another folder elsewhere on the computer, or not at all. In instances where the file could not be found and the student was required to redo the work, the students vocalized their frustration "with the computer." The research team found that the students had ongoing trouble with naming the files with a distinguishable name as well as putting the files into a common folder. The students often created names unrelated to the file (i.e., "Trev" on a photo image of a picture of pasta), and saved the file to wherever the computer opened up.

Once the source documents were created, the PowerPoint of the recipe book and the PowerPoint of the recipe format, each student was assigned an individual section or chapter of the book for which they were responsible. Their responsibilities included the creation of the recipes for the meals as well as the

related pictures. We created a spreadsheet to help the students track their individual and group recipe and picture needs. The students enjoyed using the technology and were proud of their creations, frequently wanting to show the other students the auras they had created. In the post-project interview, the teacher reflected on the creation of the recipe book and the cooking/life skills unit, commenting that,

The decline of traditional shop based classes have had a detrimental effect on students-at-risk [who] often have limited academic successes, and these environments provide those students with positive experiential learning, and skills that they would be able to carry with them into post-secondary opportunities.

Additional observations and summary of findings are highlighted in Figure 4. 


\begin{tabular}{|c|c|}
\hline INSTRUCTION & \begin{tabular}{|l} 
OBSERVATIONS / INSTRUCTION NEEDS \\
\end{tabular} \\
\hline Review other recipe books & First time many had looked at recipe book. Interest in food pictures. Excitement of the unit noted \\
\hline Plan what the book should look like & Format discussions, landscape vs portrait orientation, size of paper, layout \\
\hline Set goals for end product & Timelines, Where to file finished pieces for easy access \\
\hline $\begin{array}{l}\text { Create checklist for creation of recipe } \\
\text { book }\end{array}$ & What pictures \& recipes were needed, visualize end product \\
\hline Assign roles \& responsibliities & Ownership of each section of recipe book, importance of formatting and saving work \\
\hline \multirow[t]{8}{*}{ Digital literacy instruction } & $\begin{array}{l}\text { Find PowerPoint and Word on their computer / Open application / Save a file/ Name a file/ Create a folder on their computer/ Find a file } \\
\text { from within a different program }\end{array}$ \\
\hline & Students with board allocated technology did not have expected digital skillsets \\
\hline & Need for ongoing and repeated digitial skills to ingrain knowledge \\
\hline & Students repeatedly "lost" files in their computers / did not save work \\
\hline & Student frustration with "technology" when they did not save/ had to redo \\
\hline & Researcher intervention needed to search within computer for work saved elsewhere \\
\hline & Students had trouble with naming the file and remembering what they had named it/ where they had filed it \\
\hline & Students often named their files with names unrelated to the work, thus making it more difficult to find \\
\hline \multirow{3}{*}{ AR RECIPE BOOK - Compiling Information } & Each student had responsibility for one chapter of the book \\
\hline & Organizational and executive functioning skills were needed to keep track of their work \\
\hline & Use of tracking spreadsheet to assist students throughout the duration of the study \\
\hline \multirow[t]{5}{*}{ Creation } & Taking / Manipulating pictures \\
\hline & Creating recipes \\
\hline & Saving recipe files from powerpoint to jpeg \\
\hline & Creating Chapter titles and Title pages \\
\hline & Ensure each recipe had multiple pictures to select from \\
\hline \multirow[t]{16}{*}{ Challenges } & Use of MS Powerpoint template to create recipes was difficult to use for most students \\
\hline & Students often looked to the teacher/researcher when the work became challenging - exhibiting a lack of resilience \\
\hline & One student took a particular interest in cooking throughout and exhibited leadership not seen otherwise \\
\hline & $\begin{array}{l}\text { One student who appeared to have greatest understanding of saving/naming of files was found to have not grasped the skills and needed } \\
\text { to redo much work }\end{array}$ \\
\hline & Students enjoyed taking pictures using the ipad \\
\hline & Students were observed to have sort attention when facing difficulty \\
\hline & Students did not always test their augmentations \\
\hline & Students lacked resilience to determine why augmentations did not always work \\
\hline & Students did not transfer the difference between augmentations that worked and those which did not work \\
\hline & students rushed through the creation of the recipes and needed much prodding to fix error \\
\hline & Student " $\mathrm{D}$ " created a number of augmented pictures that he did not include in the recipe book \\
\hline & $\begin{array}{l}\text { Students (female in this study) who did not spend a lot of time using computers outside of the classroom, were not as comfortable using } \\
\text { augmented reality, nor were they willing to persevere }\end{array}$ \\
\hline & Some students were finished their portion of the recipe book quickly and were ready to move on to something new \\
\hline & The researcher needed to provide significant group and hands on assistance to ensure the full recipe book was completed \\
\hline & $\begin{array}{l}\text { One student did not complete their section of the recipe book - The teacher highlighted that "students who were struggling were unable to } \\
\text { 'fly beneath the radar' to avoid the assigned work }\end{array}$ \\
\hline & $\begin{array}{l}\text { Students were forced to troubleshoot, backtrack and find mistakes, as there were times when the 'teacher' did not necessarily have the } \\
\text { answers. }\end{array}$ \\
\hline \multirow[t]{4}{*}{ Final Reflections } & "I liked eating the food", and "I feel like I can cook this at home", and "I can't wait to show my dad the recipe book \\
\hline & The researcher noted that the students did not focus or discuss the technology skills they had acquired through making the recipe book. \\
\hline & By the end of the project, 4 of 6 students were able to complete auras without additional assistance \\
\hline & At the end of the project, all students had the required skillsets to effectively navigate AR books and images \\
\hline
\end{tabular}

Fig. 4: Summary of observations and instruction needs throughout the AR recipe book creation process.

\section{Development of 21st Century Competencies}

Through the development of the recipe book, the students had the opportunity to both learn some basic cooking skills as well as to develop some basic digital literacy skills using the AR software Aurasma. The development of the AR recipe book provided an opportunity to develop and assess students' critical thinking through an authentic, real-world learning task. As outlined in the 21 st Century Competencies Foundation Document for Discussion, the use of immersive media and simulation to offer key transformational learning practices and contexts can offer students the ability to develop 21C competencies such as cooperation, conflict resolution, curiosity, grit and perseverance, self-efficacy, problem solving, and critical thinking (Ontario Public Service, 2016). This study using augmented reality as an immersive media revealed a number of findings specific to the development of 21C competencies demonstrating student gains in critical thinking and problem-solving, grit and perseverance, cooperation/collaboration, and communication (Ontario Public Service, 2016). 
Critical thinking/problem solving. Critical thinking and problem solving were areas of focus for the teacher to develop within the class. Due to the students' life circumstances, there were ongoing situations within the class setting that demonstrated a lack of resilience or learned helplessness. The development of the AR recipe book provided an opportunity to develop the students' confidence in health and nutrition through a practical unit on cooking. The students were asked how they were good at problem solving and what strategies they employed to solve problems which arose during the creation of the AR recipe book. Each student indicated that they would try to figure things out, but when they couldn't they would ask the teacher, the researchers, or another student for help. We observed that in the beginning, the students would often ask for help without trying to figure out a solution for themselves. Over the course of the study, we found that, with ongoing encouragement and positive reinforcement, the students would try for longer periods of time before asking for assistance. We asked the students to reflect on the strategies they employed when faced with a problem. Their responses include: "using the computer to find answers"; "I would go to other peers if they knew what they were doing. I would think back to what I did before to see if it related to what I was doing in any way"; "I've learned to breathe when I get frustrated. I need to ask for help when I have a problem. When I got stuck with the computer, I thought about what I had done before and that helped"; "I would reread the question"; and simply "Try to do it." These strategies were a definite evolution from their habit of immediately asking for teacher or researcher assistance.

The teacher also highlighted gains in her own problem solving. She commented,

Being a part of creating the cookbook forced me to face my own limited skills with the technology. Not having to use the augmented reality program initially left me less than adept in using the program, and I found that I had to depend on the students to teach me.

She went on to underscore that the students played a big role in helping her to overcome her own problems as she reflected that, "drawing on previous learning is helpful. Knowing how to use the technology for me is so important, that I can, in turn, help my students when they get stuck."

Grit and perseverance. An important component of the students' program involves learning how to learn, becoming self-aware, developing resilience, and demonstrating strategies to overcome challenges. As previously noted, through the development of the recipe book, the students had the opportunity to both learn some basic cooking skills and develop some basic digital literacy skills (Figure 1) through the use of the AR software Aurasma. There were multiple times throughout the creation of the recipe book that grit and perseverance were demonstrated and developed. Through the final reflections interview with the students, they were asked if they felt that they were able to take responsibility for their own learning and what that meant to them. One student responded that he took ownership over his learning by "putting effort into it and being proud of my work." Another commented, "I take responsibility for the actions I make, and for my work." Reflecting on the importance of being a lifelong learner, one student said, "Learning is good; it helps you a lot. You learn many things in school. I would never cheat off something, I would ask for help." Another student commented on the importance of being responsible to her peers: "I don't know, it's just that doing everything with my classmates, cause if I didn't do my part I wouldn't be a part of the cookbook." All of these comments suggest that the experience of cocreating 
the augmented cookbook not only enhanced their learning of basic skills, but also contributed to their understanding of themselves and their roles as learners.

The final reflection interview also revealed an increase in perseverance. One student remarked, "Even though something is hard I still try and not give up on it. I have second doubts but I don't give up." Another student observed, "In my old school I wouldn't do the work. Now I get more help, and get things explained to me properly" and "I put all my effort into making the cookbook." The teacher also noted, "It's all about being responsible for my learning of new technology, persevere when it gets a little difficult, and put more effort into my learning."

Interview data also suggested that students felt confident in their abilities and were able to articulate their strengths and challenges as they related to the creation of the AR recipe book. Each student highlighted their successes in creating their avatars and taking and augmenting the pictures for their section of the recipe book. The students required assistance throughout the recipe creation portion of the study where they struggled to create a step-by-step recipe themselves, as well as to then type the recipe into the provided Microsoft PowerPoint template. One student highlighted his confusion over choosing corresponding photos for his section of the book. He had augmented pictures within the Aurasma program, yet he had chosen different pictures to put on his page in the cookbook. Once he realized that the pictures he had augmented were not the ones he had selected to go into the cookbook, he needed to go back to redo his pages for the AR recipe book to ensure the pictures he had augmented were the same as the ones in the book. When the students were asked if there was anything they would have done differently, they all agreed that they would not have changed anything; although one student did note she would have changed the sour cream biscuits to something else!

Cooperation/collaboration. The development of the AR recipe book required the students to cooperate extensively with one another. They were required to work together with the teacher, researchers, and each other, to select the meals that the class would prepare. This process involved discussions ranging from the cost of the ingredients, the difficulty of the meal preparation, the availability of meal preparation space and appliances, and the amount of time the students had in class to prepare the meal. The students were further required to select a chapter of the AR recipe book for which they would be responsible for the recipe selection, the photographs of the meal preparation process, and the augmentation of the recipe book. Students were required to work together and one student in particular, who struggled with sharing his learning and expertise with the class, noted: "I did get frustrated when people wanted to use what I did and I didn't want them to get credit for what I created." This student became increasingly cooperative over the duration of the AR recipe book creation and, in the end, demonstrated notable gains in his ability to share and interact with the other students.

It is important to note that there was one instance where a student was not attending class, nor completing her work and lost the privilege of participating in the AR recipe book. This decision was not made quickly or lightly; however, the natural consequence of not being a part of the book as a result of a failure to complete the work, even with multiple offers of assistance, was determined to be the appropriate course of action by the teacher and youth worker. This situation was a challenge for the class because the teacher was required 
to pick up the slack to complete the section of the recipe book that had originally been assigned to this student. The teacher then commented: "As far as my responsibility for the learning of augmented reality, I must admit I was lacking and would fall back on the excuse that I had so many other things to do." She found that she had not learned alongside the students and when she needed to take over the student's chapter in the book, she required assistance from the research team in the completion of the book.

Communication. Throughout the development of the AR recipe book, the students learned how to effectively navigate digital tools. They were asked how working with the researchers could potentially help them in their future learning and whether learning through technology might help in future school years. One student reflected that he felt he would have a head start for next year as he could take his learnings from this year and apply them to his integration tech class the following year. Another student indicated he knew more about technology now because he was able to navigate digital tools such as YouTube and Google to find information. A third student stated that she now knew how to augment pictures and would "probably" use AR to show her learning next year, while a different student reflected that the experience provided an opportunity to be introduced to new technology that she had not seen before. The teacher stated: "I will teach/encourage my students to use AR next year to create interesting and unique assignments" and thought that, "using AR [allowed the students] to present their learning in creative ways." One student expressed that she didn't know how technology would help her in the future.

\section{Discussion}

This study has focused on creating with AR in a life skills curriculum or "STEAM (Science, Technology, Engineering, Arts, \& Math)" related context. This research suggests that the use of AR crosses multiple curricular areas as employing the creation of auras to demonstrate understanding or provide additional information is not subject specific. Furthermore, the consideration of AR technologies in K-12 schooling completed through this study has demonstrated the need to consider specific instructions on basic digital skill sets such as Internet navigation, digital citizenship, saving, naming, and retrieving and attaching files.

As new technologies emerge, their usefulness in educational contexts will be continuously examined. As demonstrated through this study, some students lack very basic digital skills that are integral to their capabilities to use AR, VR, and other digital technologies, despite our assumptions that students are proficient users of a variety of tools and programs. Preparing students today for future careers requires that those responsible for curriculum acknowledge the integral role that technology plays in both the world today and the employment prospects of the future. Regular references to how "tech savvy" today's youth tends to focus on their inherent ability to navigate social media, and perhaps their greater aptitude to pick up technology skills quickly. 
Curriculum connections and using AR technologies in the classroom. This study has demonstrated that AR creation can be integrated into a life skills / food curriculum and has highlighted the potential for AR to cross multiple subject and curriculum areas. The teacher in this study reflected on the learning that occurred through the development of the recipe book,

The potential for students to direct the learning process from the beginning to end - design to producing the end product, should be the practice in the classroom. It would afford students the opportunity to connect to the experience in ways that the teacher-directed approach would not.

Furthermore, the teacher noted that this kind of inquiry-based project helps facilitate the development of important transferable skills or 21 st century skills.

These projects are a perfect opportunity to observe the learning skills students are using collaboration, responsibility, initiative, organization, independent work, self-regulation - which are crucial to student development, and projects such as these serve to provide opportunities to grow in these areas ... Students at risk are already at a disadvantage in finding employment upon graduation from high school. Increasing the educational requirements for apprenticeship programs, coupled with not providing early education/exposure to technology, will only serve to further minimize their ability to succeed.

These 21 st century skills have also been called "soft-skills" or noncognitive skills. We argue that this is a misnomer and suggest that these transferable skills are the permanent, lifelong skills that students need to develop to be successful, not only at school, but also at work and in life.

Need for a deeper understanding of technology. Although technology is prevalent in youth's lives today, there appears to be a superficial understanding of the technology itself. This is not a generalizable statement as there are obviously many youths who have significant skill using digital technologies. Educators need to determine what role schools should play in the development of a common digital skill set. Emerging technologies such as AR can only be used effectively when students have a basic level of digital understanding and skills. The lack of uniform instruction in these basic skill sets was evident in this study. For this group of marginalized students, this was especially troubling as the students in this study have daily access to school district supplied laptops intended to support their learning.

\section{Conclusion}

Many examples already exist to display where the future of AR may take us. The release of Nintendo/Niantic's Pokémon Go in July 2016 resulted in the global adoption of augmented reality (AR) technologies, almost overnight (Ore, 2016). In what can be best described as a rapid, perhaps herd-like, diffusion (Rogers, 2003), Pokémon Go gathered an estimated 21 million users in the first two weeks in the United States alone (Sillis, 2016). The collision of technology advancements and increased smartphone user base created the perfect storm for the diffusion of AR technology through Pokémon Go (Poushter, 2016).

AR apps such as 4D anatomy and 4D Elements provide augmentations of the human body and heart, as well as elemental chemistry (Daqri, 2016a, 2016b). Aurasma and Layar allow students to develop 
their own augmentations easily through free and accessible software offerings (Hewlett-Packard Development Company, 2016; Blippar, 2016). As Lin et al. (2016) point out, "AR technologies can take any situation, location, environment or experience to a new level of meaning and understanding" (p. 51), while augmenting the real world in real time, potentially applying a sense of smell, touch, and hearing (Carmigniani et al., 2011). These technologies allow learners the opportunity to learn in dynamic hands-on ways, shifting instruction from passive observation to active learning. As highlighted in the 2017 K-12 Edition of the Horizon Report, the advance of technology is not only providing new considerations and tools for instruction, but also new opportunities for multidimensional assessment (Freeman et al., 2017). AR (VR and MR) technologies may also lend themselves well to the provision of authentic learning opportunities through learner immersion via augmentation and simulation of realworld environments and scenarios (Freeman et al., 2017). The development of digital literacy skills and greater understanding of digital citizenship are both areas which may benefit from the use and creation of AR. Wu et al. (2013) highlight that in the future, consideration of AR should not be limited to a type of technology, but rather that one should consider AR as an "affordance[] of the real world [which provides] additional and contextual information that augments learners' experiences of reality" (p. 43). An augmented world offers many exciting and intriguing opportunities for learners today and beyond.

\section{References}

Adams Becker, S., Cummins, M., Freeman, A., \& Rose, K. (2017). 2017 NMC Technology Outlook for Nordic Schools: A Horizon Project Regional Report. Austin, Texas: The New Media Consortium. Retrieved from https://www.nmc.org/publication/2017-nmc-technology-outlook-nordic-schools/

Assefa, S., \& Gershman, L. (2012). 21st-century skills and science education in K-12 environment: Investigating a symbiotic relationship. Curriculum and Teaching Dialogue, 14(1-2), 139.

Azuma, R. T. (1997). A survey of augmented reality. Presence: Teleoperators \& Virtual Environments, 6(4), 355-385. doi:10.1162/pres.1997.6.4.355

Bacca, J., Baldiris, S., Fabregat, R., Graf, S., \& Kinshuk. (2014). Augmented reality trends in education: A systematic review of research and applications. Journal of Educational Technology \& Society, 17(4), 133.

Barden, O. (2014). Facebook levels the playing field: Dyslexic students learning through digital literacies. Research In Learning Technology, 22. doi:http://dx.doi.org/10.3402/rlt.v22.18535

Barone, D. (2015). The fluid nature of literacy: A look at how the definition of literacy has changed, and what it means for today's students. Literacy Today, 33(1), 6.

Blippar. (2016). Layar [Mobile Application Software]. Retrieved from https://www.layar.com/

Bower, M., Howe, C., McCredie, N., Robinson, A., \& Grover, D. (2014). Augmented reality in education Cases, places and potentials. Educational Media International, 51(1), 1-15. doi:10.1080/09523987.2014.889400 
Bujak, K. R., Radu, I., Catrambone, R., Macintyre, B., Zheng, R., \& Golubski, G. (2013). A psychological perspective on augmented reality in the mathematics classroom. Computers \& Education, 68, 536-544. doi:10.1016/j.compedu.2013.02.017

Carmigniani, J., Furht, B., Anisetti, M., Ceravolo, P., Damiani, E., \& Ivkovic, M. (2011). Augmented reality technologies, systems, and applications. Multimedia Tools and Applications, 51(1), 341-377. doi:10.1007/s11042-010-0660-6

Chen, P., Liu, X., Cheng, W., \& Huang, R. (2016). A review of using augmented reality in education from 2011 to 2016. In Innovations in Smart Learning (Lecture Notes in Educational Technology, pp. 13-18). Singapore: Springer. doi:10.1007/978-981-10-2419-1_2

Chu, S. K. W., Reynolds, R. B., \& Tavares, N. J. (2016). 21st century skills development through inquirybased learning. Springer: Singapore.

Comstock, E. (2013). Constructivism. In J. Ainsworth (Ed.), Sociology of education: An a-to-z guide (Vol. 2, pp. 151-152). Thousand Oaks, CA: SAGE Publications Ltd. doi:10.4135/9781452276151.n87

Daqri. (2016a). 4D Anatomy [Mobile application software]. Retrieved from http://anatomy4d.daqri.com/ Daqri. (2016b). 4D Elements [Mobile application software]. Retrieved from http://elements4d.daqri.com/

Downing, J. E. (2005). Teaching literacy to students with significant disabilities: Strategies for the K-12 inclusive classroom. Thousand Oaks, CA: SAGE Publications Ltd. doi:10.4135/9781483328973

Erten, O., \& Savage, R. S. (2012). Moving forward in inclusive education research. International Journal of Inclusive Education, 16(2), 221-233. doi:10.1080/13603111003777496

Freeman, A., Adams Becker, S., Cummins, M., Davis, A., \& Hall Giesinger, C. (2017). NMC/CoSN Horizon Report: 2017 K-12 Edition. Austin, Texas: The New Media Consortium.

Gelenbe, E., Hussain, K., \& Kaptan, V. (2005). Simulating autonomous agents in augmented reality. The Journal of Systems \& Software, 74(3), 255-268. doi:10.1016/j.jss.2004.01.016

Herold, B. (2014). Oculus rift fueling new vision for virtual reality in K-12; but critics question educational value. Education Week, 34(2), 10. Retrieved from http://www.edweek.org/ew/articles/2014/08/27/ 02oculus.h34.html

Hew, K. F., \& Cheung, W. S. (2010). Use of three-dimensional (3-D) immersive virtual worlds in K-12 and higher education settings: A review of the research. British Journal of Educational Technology, 41(1), 33-55. doi:10.1111/j.1467-8535.2008.00900.x -1-4614-0064-6

Hewlett-Packard Development Company. (2016). Aurasma [Mobile Application Software]. Retrieved from https://www.Aurasma.com/

Kerawalla, L., Luckin, R., Seljeflot, S., \& Woolard, A. (2006). "Making it real": Exploring the potential of augmented reality for teaching primary school science. Virtual Reality, 10(3), 163-174. doi:10.1007/s10055-006-0036-4

Kong, SC, Chan, TW, Griffin, P, Hoppe, U, Huang, RH, Kinshuk Looi, CK, et al. (2014). E-learning in school education in the coming 10 years for developing 21 st century skills: Critical research issues and policy implications. Educational Technology \& Society, 17(1), 70-78. 
Larson, L. C., \& Miller, T. N. (2011). 21st century skills: Prepare students for the future. Kappa Delta Pi Record, 47(3), 121-123. doi:10.1080/00228958.2011.10516575

Lee, K. (2012). Augmented reality in education and training. Boston, MA: Springer. doi:10.1007/s11528-012-0559-3

Lin, C., Lin, C., Chai, H., Wang, J., Chen, C., Chen, C., et al. (2016). Augmented reality in educational activities for children with disabilities. Displays, 42, 51-54. doi:10.1016/j.displa.2015.02.004

Lindgren, R., \& Johnson-Glenberg, M. (2013). Emboldened by embodiment: Six precepts for research on embodied learning and mixed reality. Educational Researcher, 42(8), 445-452. doi:10.3102/0013189X13511661

Mihelj, M., Novak, D., \& Beguš, S. (2014). Virtual reality technology and applications (2014th ed.). Dordrecht: Springer Netherlands. doi:10.1007/978-94-007-6910-6

Minton, P. (2002). Using information and communication technology (I.C.T.) to help dyslexics, and others, learn spelling. Australian Journal of Learning Disabilities, 7(3), 26. doi:10.1080/19404150209546705

Ontario Public Service. (2016). Phase 1 - Towards defining 21st century competencies for Ontario: 21 st century competencies - Foundation document for discussion. [Online Document]. Retrieved from http://www.edugains.ca/resources21CL/About21stCentury/21CL_21stCenturyCompetencies.pdf

Ore, J. (2016, July 12). Pokémon Go brings augmented reality to the mainstream: Nostalgia combined with accessible technology makes Nintendo's new app an overnight smash. CBC News. Retrieved from http://www.cbc.ca/news/technology/pokemon-go-augmented-reality-watershed-moment-1.3674204

Poushter, J. (2016, February 22). Smartphone ownership and Internet usage continues to climb in emerging economies. Pew Research Centre. Retrieved from http://www.pewglobal.org/2016/02/22/ smartphone-ownership-and-internet-usage-continues-to-climb-in-emerging-economies/

Radu, I. (2014). Augmented reality in education: A meta-review and cross-media analysis. Personal and Ubiquitous Computing, 18(6), 1533-1543. doi:10.1007/s00779-013-0747-y

Rogers, E. M. (2003). Diffusion of innovations (5th ed.). New York, NY: Free Press.

Sigrist, R., Rauter, G., Riener, R., \& Wolf, P. (2013). Augmented visual, auditory, haptic, and multimodal feedback in motor learning: A review. Psychonomic Bulletin \& Review, 20(1), 21-53. doi:10.3758/s13423-012-0333-8

Sillis, B. (2016, July 27). The mind-blowing numbers behind Pokémon GO. [Blog post]. Retrieved from http://www.redbull.com/ca/en/games/stories/1331808575906/pokemon-go-8-huge-stats

Swadener, B. (2010). "At risk' or 'at promise'? From deficit constructions of the 'other childhood' to possibilities for authentic alliances with children and families." International Critical Childhood Policy Studies, 3(1), 7-29.

Teichner, A. (2014). Augmented education: Using augmented reality to enhance K-12 education. Paper presented at the Proceedings of the 2014 ACM Southeast Regional Conference (ACM SE '14). 45. (1-3). New York, NY. doi:10.1145/2638404.2638519 
Thornton, T., Ernst, J. V., \& Clark, A. C. (2012). Augmented reality as a visual and spatial learning tool in technology education: Potential exists for AR to be incorporated in not only STEM education, but across all disciplines. Technology and Engineering Teacher, 71(8), 18.

Voogt, J., \& Pareja Roblin, N. (2012). A comparative analysis of international frameworks for 21 st century competences: Implications for national curriculum policies. Journal of Curriculum Studies, 44(3), 299-321. doi:10.1080/00220272.2012.668938

Wu, H., Lee, S. W., Chang, H., \& Liang, J. (2013). Current status, opportunities and challenges of augmented reality in education. Computers \& Education, 62, 41-49. doi:10.1016/j.compedu.2012.10

Zhao, Y. (2015). A world at risk: An imperative for a paradigm shift to cultivate 21 st century learners. Society, 52(2), 129-135. doi:10.1007/s12115-015-9872-8

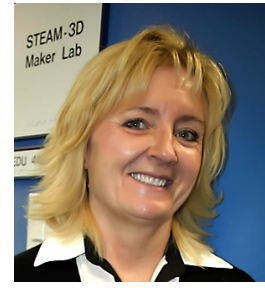

Janette Hughes is Canada Research Chair, Technology and Pedagogy and Professor in Digital Literacies at the University of Ontario Institute of Technology where she teaches and conducts research in the Faculty of Education. Her research and teaching interests include: critical digital literacies, digital making, adolescent literacies and identity, writing and digital media, new literacies and conceptualizations of learning, and digital citizenship. Hughes has published her research widely and authored a book for school administrators called The Digital Principal.

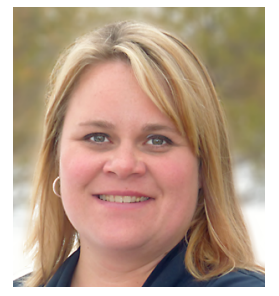

Melanie Maas has a unique blend of technology and education experience. Through almost 20 years in the technology industry at IBM and Lenovo, Melanie worked in a variety of progressive sales, marketing, operations, and training roles. She is in her final month of completion of a Master of Education (Digital Literacies) degree at the University of Ontario Institute of Technology. Over the last year and a half, Melanie has focused her research interests on the use of Augmented, Virtual, and Mixed Reality (AR/VR/MR) technologies and their applications and affordances for learning. Melanie is innovative, forward-thinking, and passionate about the possibilities for technology to truly transform what it means to teach and learn in the 21 st century. 
170 | LEARNing Landscapes | Autumn 2017, Vol. 11 No. 1 